\title{
Evaluation of bone-implant interfaces on iso5832-9 and ti6al4v alloys after thin-anodic oxide film growth
}
T. C. da Costa'
H. A. Ponte'
L. A. Taminato'
C. E. B. Marino'

A. R. S. Gomes'

\section{Abstract}

Introduction: Titanium alloys and seeveral stainless steels show good performance when used in orthopedic replacements due to their excellent properties, such as mechanical strength and corrosion resistance. The aim of this study was to evaluate the implant-bone interface on ISO 5832-9 and Ti6Al4V alloys electrochemical treated. Methods: The growth of oxides was carried out on stainless steel ISO 5832-9 up to1.0V in phosphate buffered saline and Ti6Al4V alloy up to $5.0 \mathrm{~V}$, at room temperature. Scanning electron microscopy (SEM) was used for qualitative characterization. The in vivo experiment was conducted with rats divided into 3 groups: untreated surface-Control (Group 1); anodic oxide grown up to $1.0 \mathrm{~V}$ for ISO 5832-9 and up to 5.0V for Ti6Al4V (Group 2); anodic oxide grown up to $1.0 \mathrm{~V}$ for ISO $5832-9$ and up to $5.0 \mathrm{~V}$ for Ti6Al4V and surface activation with hydroxyapatite (Hpa) in SBF (10 days) for both materials (Group 3). The implants were inserted in tibia by surgery. After 6 weeks the animals were euthanized and tibia processed for SEM. Results: Ti6Al4V alloy had a typical valve's metal behaviour due to stable oxide titanium growing as barrier. ISO 5832-9 stainless steel showed stable oxide but as a thinner film irregularly distributed on the surface of implants. These behaviours were consistent with in vivo test which showed uniform bone matrix deposition on the Ti6Al4V surface of bone

1 Federal University of Paraná, Curitiba, Paraná, Brazil. 
implants. There is not implant-bone interface when titanium alloy was subjected to anodizing or anodizing/Hpa. Discussion: potentiodynamic titanium oxides enhanced the osseointegration process.

Keywords: titanium alloys; bone tissue; osseointegration; scanning electron microscopy

\section{Introduction}

It has been investigated the viability of using materials compatible with the human body with the aim of accelerating the recovery process of the tissues, especially bone healing (Amini et al., 2012). The most commonly surgical materials used for this purpose are stainless steel and titanium alloys for manufacturing endosseous implants (Villamil et al., 2002). These biomaterials have demonstrated some efficiency and the surface modifications have been shown to enhance osseointegration at early implantation times, but the underlying mechanisms of bone-implant interfaces are still not elucidated (Novaes et al., 2010 and Yun et al., 2010). Stainless steel is most used because of its low cost, while titanium and titanium alloys provide better chemical and mechanical biocompatible properties improving biological response but it costs higher than stainless steel (Liu and Chu, 2004; Franco et al., 2008). The favorable biological response of these biocompatible materials is attributed to the spontaneous presence of an oxide film on their surfaces (Liu \& Chu, 2004; Novaes et al., 2010). Anodic oxidation by electrochemical has been reported to be the favored method to obtain thick and porous oxide films but the thin-potentiodynamic oxide effect are not completely known (Yun et al., 2010; Yang et al., 2004). Also, there are some evidences that the anodic oxidation is responsible for enhancing the bone formation between implant-tissue, however, the methods to induce surface's treatment have used steady conditions up to high potentials and currents in a very concentrated acid's solution (Buser et al., 1999; Sul, 2003; Liang et al., 2003). Some studies have shown that thicker oxide films are formed on the Ti and Ti alloys by applying a steady potential or current (Novaes et al., 2010; Lin et al., 2013; Szesz et al., 2013). Nevertheless, using the potentiodynamic method, it is possible to obtain anodic oxides with thin layers, improving their electrochemical parameters and also enhancing their stability properties (Marino \& Mascaro, 2004; Marino et al., 2001). It has been shown that the composition, structure and thickness of the films determine their stability and bioactivity (Villamil et al., 2002).

In vivo tests with rats have indicated that titanium implant surfaces can exhibit bone-bonding by an increase in the complexity of the surface topog- 
raphy (Mendes et al., 2007; Yun et al., 2010; Davies et al, 2014). However, to knowledge it is still unexplored the effects of Ti6Al4V and ISO 5832-9 surfaces submitted to electrochemical treatment in bone-implant interfaces. Thus, the present study focused on evaluating the relationship between surfaces treated implants of Ti6Al4V and ISO 5832-9 stainless steel in vitro and in vivo.

\section{Materials and methods}

\subsection{Sample surface preparation}

The working electrodes were Ti6Al4V-ELI alloy discs (C 0.010\%; N 0.002\%; $\mathrm{H} 0.004 \%$; Fe 0.180\%; O 0.102\%; Al 5.960\%; V 4.000\%; Ti bal.) from Realum Ltda., Brazil and ISO 5832-9 stainless steel sheet (C 0.015\%; Si 0.330\%; Mn 4.09\%; Cr 20.07\%; Ni 9.94\%; Mo 2.50\%; N 0.32\%; P 0.014\%; S 0.005\%; Nb $0.285 \%$; Fe bal.) from Sandinox Ltda., Brazil. Both the electrodes were mechanically polished with a grade 1200 silicon carbide paper and rinsed with acetone, ethanol and distilled water.

\subsection{Surface treatment and characterization}

The measurements were taken using Microquimica Potentiostatic/Galvanostatic (model MQPG-01) equipment. The initial and final potentials were -1.0 $\mathrm{V}$ and $5.0 \mathrm{~V}$ (vs. ECS) for Ti6Al4V and $-1.0 \mathrm{~V}$ and $1.0 \mathrm{~V}$ ( $v$ s. ECS) for the ISO $5832-9$ stainless steel, for potentiodynamic growth at $50 \mathrm{mV} / \mathrm{s}$ and $10 \mathrm{mV} / \mathrm{s}$, respectively. The electrolyte was PBS (phosphate buffered saline - $\mathrm{NaCl} 8.77 \mathrm{~g}$ $\mathrm{L}^{-1} ; \mathrm{Na}_{2} \mathrm{HPO}_{4} 3.58 \mathrm{~g} \mathrm{~L}^{-1}, \mathrm{KH}_{2} \mathrm{PO}_{4} 1.36 \mathrm{~g} \mathrm{~L}^{-1}, \mathrm{pH}$ 6.9) solution at room temperature. The conventional three-electrode cell with an exposed area of $0.28 \mathrm{~cm}^{2}$ for the working electrode (the surface polished and rinsed as described) with a platinum electrode as the counter electrode was used, and all the potentials were measured with a saturated calomel electrode (SCE). After all the electrochemical samples had been treated, some of the samples were immersed in SBF for 10 days for an evaluation of the superficial bioactivity according to Kokubo (2006). All the electrochemical tests were carried out in triplicate to guarantee the accuracy and reliability of the data. Cyclic voltammetry was used to characterize the electrochemical system and the surface morphology was investigated by SEM (Scanning Electron Microscopy-Philips, XL30 model and $20.0 \mathrm{kV}$ ). The surface elements in the oxide layer were investigated by EDS (Energy Dispersive Spectroscopy-Wilo Heerbrugg). 


\subsection{In vivo study for osseointegration}

Mini implants were used in rats: the $1.2 \mathrm{~mm}$ diameter implants were cut into $4 \mathrm{~mm}$ lengths to fit the diameter of the rat tibia. The implants were divided into three Groups: untreated surface-Control (Group 1); with anodic oxide grown up to $1.0 \mathrm{~V}$ for the ISO 5832-9 and up to $5.0 \mathrm{~V}$ for Ti6Al4V (Group 2); and with anodic oxide grown up to $1.0 \mathrm{~V}$ for the ISO $5832-9$ and up to $5.0 \mathrm{~V}$ for Ti6Al4V and surface activation with hydroxyapatite (Hpa) in SBF (10 days) for both materials (Group 3) (Table 1). All the animals received an implant in their right tibias.

Table 1 Experimental Groups: Control and Surfaces Treatment

\begin{tabular}{|l|l|}
\hline \multicolumn{1}{|c|}{ Groups } & \multicolumn{1}{|c|}{ Surface Treatment } \\
\hline 1-Ti6Al4V and ISO 5832-9 stainless steel/Control & Untreated \\
\hline 2- Ti6Al4V and ISO 5832-9/0xide & $\begin{array}{l}\text { Growth the anodic oxide up to 5.0 V (Ti6Al4V) and up to } 1.0 \\
\text { V (ISO 5832-9) }\end{array}$ \\
\hline 3- Ti6Al4V and ISO 5832-9/0xide+ Hpa & $\begin{array}{l}\text { Growth the anodic oxide up to 5.0 V (Ti6Al4V) and up to } 1.0 \\
\text { V (ISO 5832-9) followed by sufface activation with Hpa in SBF } \\
\text { (10 days) to both materials. }\end{array}$ \\
\hline
\end{tabular}

Animal care and experimental procedures were carried out in accordance with the Guide for Care and Use of Laboratory Animals and approved by the Ethics Committee for Animal Research of the Federal University of Paraná (process 526). Adult male Wistar rats (average body weight of $250 \mathrm{~g}$ and 12 weeks in age) were used in this study in accordance with the reviewed ISO 109,936. All animals were kept in plastic cages under controlled conditions (12-hour light/dark cycle) with free access to a water and food pellet diet for 6 weeks, at the vivarium of the Federal University of Parana, in Curitiba, Brazil. The animals were anesthetized with an intraperitoneal injection of $95 \mathrm{mg} / \mathrm{kg}$ ketamine and $12 \mathrm{mg} / \mathrm{kg}$ xylazine. Under anesthetic's effect, the anterior-medial right tibia was cleaned with an iodine solution $(1 \%)$ and the area isolated. Then, the right proximal tibia was exposed using a medial approach by surgical instruments and soft tissues were reflected, according to a standard surgical protocol. Afterwards, a defect of $1.0 \mathrm{~mm}$ in diameter was created through a $1 \mathrm{~mm}$ drill (Adiel, model SR GX, Kavo). Finally the defect was filled with $1.2 \mathrm{~mm}$ diameter implant in the tibia (Clarke et al., 2004; Pulleo \& Nanci, 1999). 
Following the period of 6 weeks after surgery, the animals were euthanized and the tibia with the implant was removed without the surrounding tissues, and immediately fixed in a formalin solution $(10 \%)$ for 24 hours. The samples were then dehydrated and subjected to analysis of the bone/implant interface using a Scanning Electron Microscopy (SEM- Philips, model XL 30 and 20.0 kV) (Novaes et al., 2010; Pulleo \& Nanci, 1999).

\section{Results and discussion}

\subsection{Evaluation of the electrochemical behavior (in vitro)}

Cyclic voltammetry (Figure 1a) was used to evaluate the electrochemical behavior of the Ti6Al4V. This profile resembled those presented by valve metals (Marino et al., 2006). The potential varied between $\mathrm{E}_{\mathrm{i}:}-1.0 \mathrm{~V}$ and $\mathrm{E}_{\mathrm{f}}$ $5.0 \mathrm{~V}$ in PBS solution at room temperature. Voltammetry showed a very stable behavior of the oxide on the surface, demonstrating the excellent stability of the titanium (Ti6Al4V). Cyclic voltammetry was also used to evaluate the ISO 5832-9 (Figure 1b), where low potentials were used which varied between $\mathrm{E}_{\mathrm{i}}$ : $-1.0 \mathrm{~V}$ and $\mathrm{E}_{\mathrm{f}} 1.0 \mathrm{~V}$, in PBS solution at room temperature. The anodic region indicated growth of an oxide film on the surface, probably $\mathrm{Cr}_{2} \mathrm{O}_{3}$ or $\mathrm{Fe}_{2} \mathrm{O}_{3}$. However, the evolution of hydrogen could be observed in the cathodic region, at about $-0.5 \mathrm{~V}$.
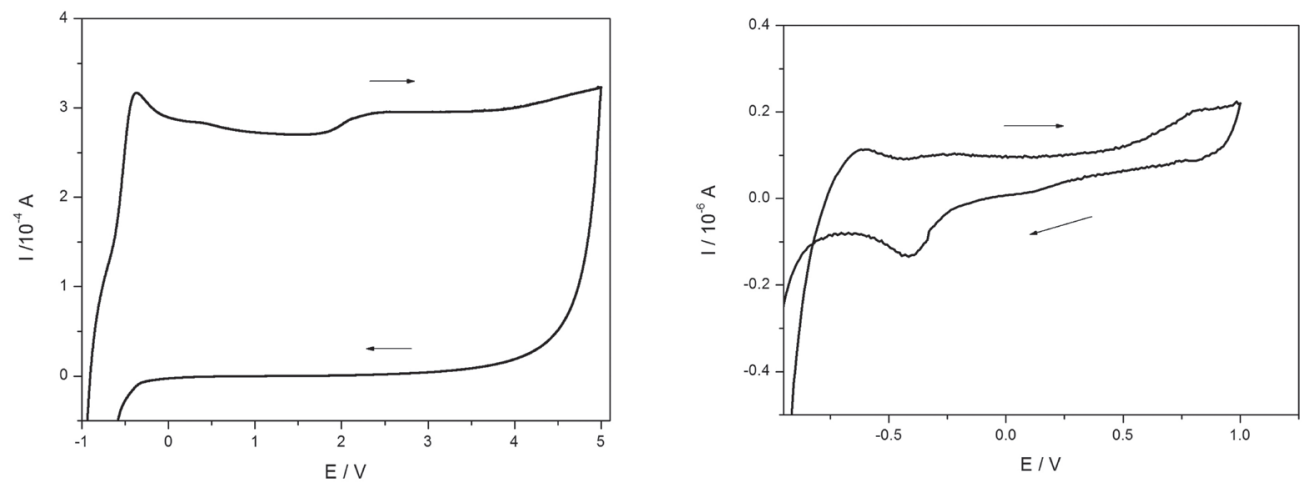

Figure 1 Cyclic Voltammetry (A) Ti6Al4Valloy, in PBS solution at 50mV/s (B) IS05832-9, in PBS solution at 10 $\mathrm{mV} / \mathrm{s}$. Surfaces polished to 1200 \# before measurement.

Using the potentiodynamic technique with low potentials, the growth of a stable oxide was observed, probably $\mathrm{TiO}_{2}$, with an anodic peak at approximately $(-0.55 \mathrm{~V})$ on the Ti6Al4V (Figure 2a). The ISO 5832-9 showed the growth 
of oxide at about $-0.7 \mathrm{~V}$ (Figure 2b), probably $\mathrm{Cr}_{2} \mathrm{O}_{3}$. After formation of the oxides (titanium and chromium oxides, respectively) the current did not vary. This behavior indicated a protective property of this type of oxide barrier. Thus, the titanium oxide formed on the surface of the Ti6Al4V alloy was stable and not to reduces due to the absence of a peak in the cathodic region. The oxide grown up to $5.0 \mathrm{~V}$ showed a thickness around $12.5 \mathrm{~nm}$, as also described in the literature (Marino et al., 2001). However, the natural oxide grown spontaneously on the Ti alloys was around $2.0 \mathrm{~nm}$ in thickness (Marino et al., 2001). The voltammogram of the ISO 5832-9 stainless steel showed the growth of a thin layer of around $3.0 \mathrm{~nm}$, which is comparable to the natural oxide (Hanawa et al., 2002; Yi et al., 2013).
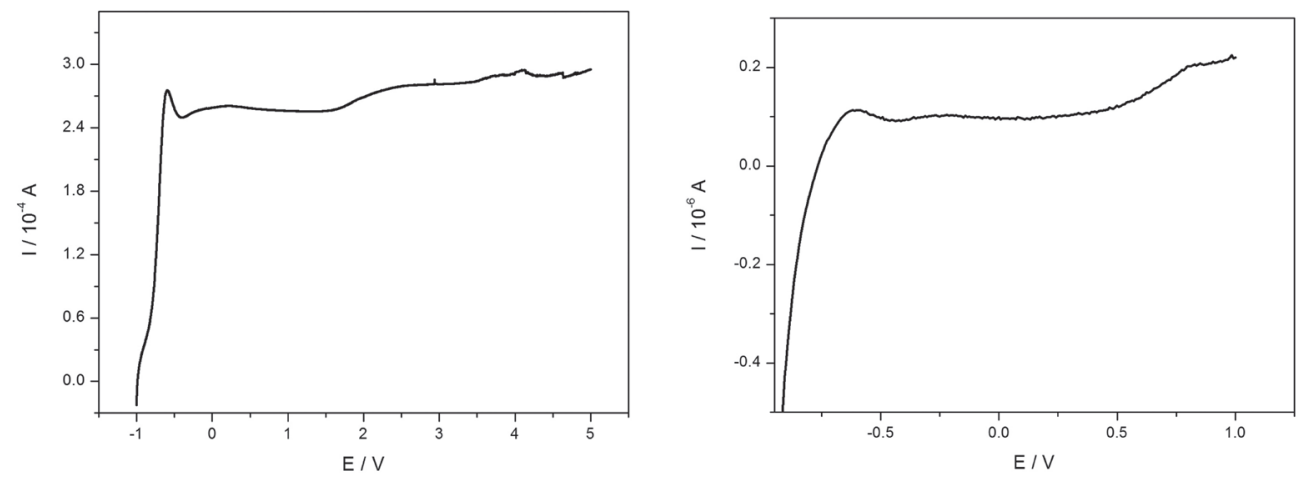

Figure 2 Voltammetric Profile (A) from -1.0 V to $5.0 \mathrm{~V}$, in PBS solution at $50 \mathrm{mV} / \mathrm{s}$ for the Ti6Al4V (B) from - $1.0 \mathrm{~V}$ to $1.0 \mathrm{~V}$, in PBS solution at $10 \mathrm{mV} / \mathrm{s}$ for the $1505832-9$. Surfaces polished to 1200 \# before measurement.

Many studies have shown that chemical treatments of the metal surfaces increase the ability for bone growth around the implant, due to better chemical interaction between the elements in the interface (Yang et al., 2004; Yu et al., 2010).

\subsection{Surface characterization - in vitro}

The Ti6Al4V and ISO 5832-9 surfaces after anodic oxides surface treatment were observed by a morphological analysis carried out using SEM (Figure 3). A thin oxide layer formed on the Ti6Al4V surface (Figure 3a), probably $\mathrm{TiO}_{2}$ grown up to $5.0 \mathrm{~V}$ (Marino et al., 2004). The presence of sandpaper grooves was observed on the ISO 5832-9 surface (Figure $3 \mathrm{~b}$ ) suggesting the formation of a very thin layer of chromium oxide. 


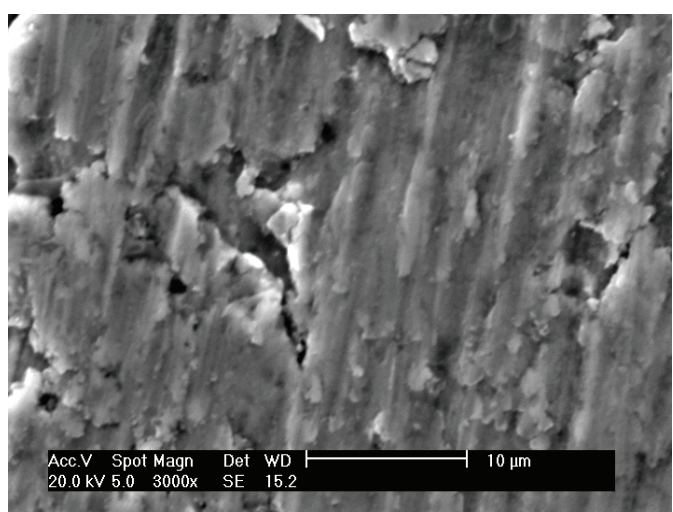

(A)

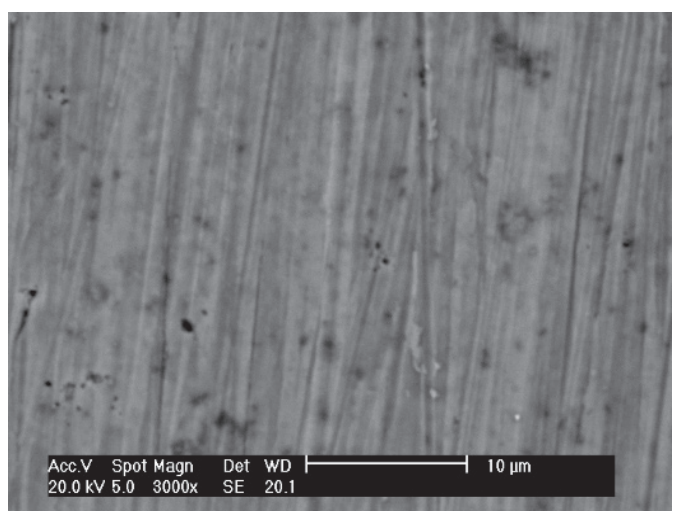

(B)

Figure 3 SEM photomicrographs. (A) Anodic oxide layer up to 5.0 Von Ti6Al4V.

(B) Anodic oxide layer up to 1.0 Von ISO 5832-9 at 3,000x.

The EDS (energy dispersive X-ray spectroscopy) results showed titanium and oxygen on the surface of the Ti6Al4V and chromium and iron on the ISO 5832-9 (Table 2).

Table 2 Composition of oxide films on Ti6Al4V and ISO 5832-9

\begin{tabular}{|l|l|}
\hline \multicolumn{1}{|c|}{ Surface composition } & \multicolumn{1}{|c|}{ (\% atomic) } \\
\hline Ti6Al4V/oxide & ISO 5832-9/oxide \\
\hline $\mathrm{Ti}-56.19$ & $\mathrm{Cr}-21.03$ \\
\hline $\mathrm{Al}-4.23$ & $\mathrm{Fe}-70.48$ \\
\hline $\mathrm{V}-2.04$ & $0-7.58$ \\
\hline $0-16.85$ & \\
\hline
\end{tabular}

In Table 2, an element referred to as oxygen was detected in both biomaterials, and it can indicate the presence of an oxide layer surface. On the Ti6Al4V alloy, the atomic percentage of the oxygen was around $16 \%$ and for the ISO 5832-9 stainless steel it was around $7 \%$. Thus, a lower atomic percentage of the element oxygen was observed on the stainless steel surface when compared with the alloy. This is probably due to the reduced thickness of the oxide layer on the stainless steel $(\sim 3 \mathrm{~nm})$ as compared to the alloy $(\sim 12.5 \mathrm{~nm})$, where the diffusion of oxygen ion was higher and evident when the potential applied was $5.0 \mathrm{~V}$. 
After 10 days immersion in the SBF solution, the surfaces with the anodic oxide grown up to low potential showed a significant deposition of globular hydroxyapatite on the Ti6Al4V (Figure 4a). However, with the ISO 5832-9/anodic oxide system grown up low potential there were no Hpa globules on the surface (Figure $4 \mathrm{~b}$ ). This indicates a reduced degree of biocompatibility of the ISO 5832-9 when compared to the Ti6Al4V/anodic oxide formed in a low potential system. Probably, this is due to the excellent interaction of the surface covered with titanium dioxide $\left(\mathrm{TiO}_{2}\right)$ and oxy-hydroxy titanium $(\mathrm{TiOOH})$ with calcium and phosphorus ions, which can provide better surface bioactivity (Kokubo et al., 1996).

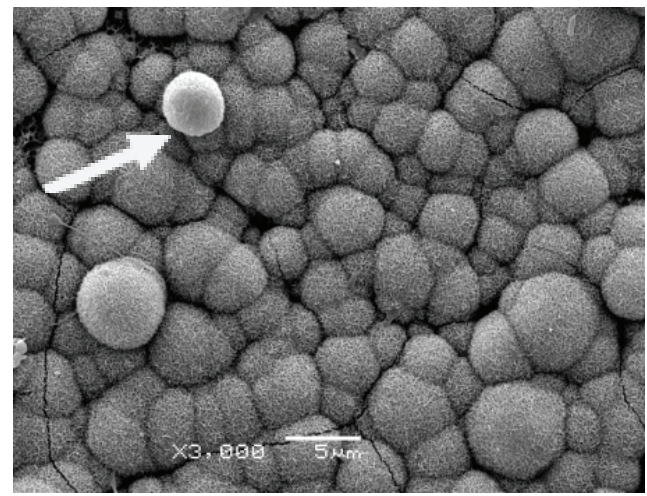

(A)

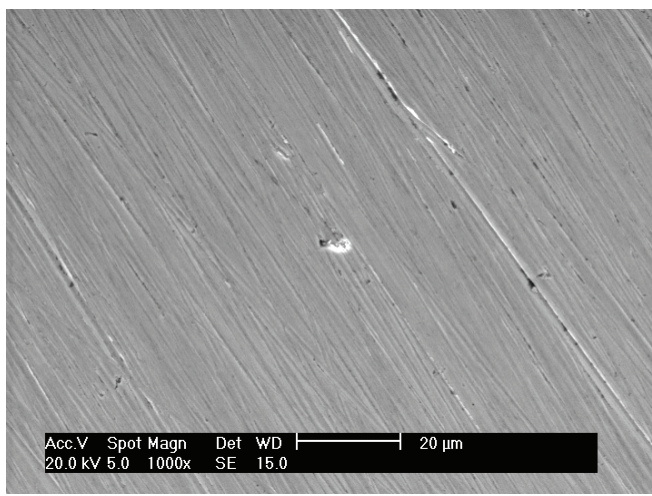

(B)

Figure 4 SEM photomicrographs. (A) Ti6Al4V/anodic oxide up low potential (5.0 V)/Hpa; presence at 3,000x, arrow shows Hpa globules (B) ISO 5832-9 /anodic oxide up low potential (1.0 V)/Hpa absence at 1,000x.

\subsection{Surface characterization - in vivo}

Six weeks after implantation of the electrochemically treated biomaterials in the rat tibia, in vivo tests were used to determine the results of the post-surgical intervention by observing the contact between the bone implant interface using photomicrographs obtained by SEM. The comparison between the groups was based on this analysis of the bone/implant interface (Clarke et al., 2004; Pulleo \& Nanci, 1999).

The SEM photomicrographs allowed analyzing the bone-implant interface and the osseointegration process. All the distances were measured in micrometers $(\mu \mathrm{m})$ between the bone and its implant using the SEM/EDS software (Table 3). SEM photomicrographs of bone implant interface Ti6Al4V/control and bone implant interface ISO 5832-9/Control showing no new bone formation can be seen in Figure $5 \mathrm{~A}$ and B, respectively. 


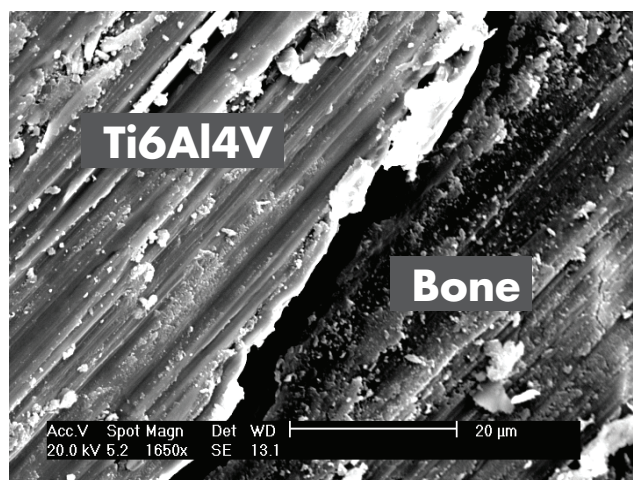

(A)

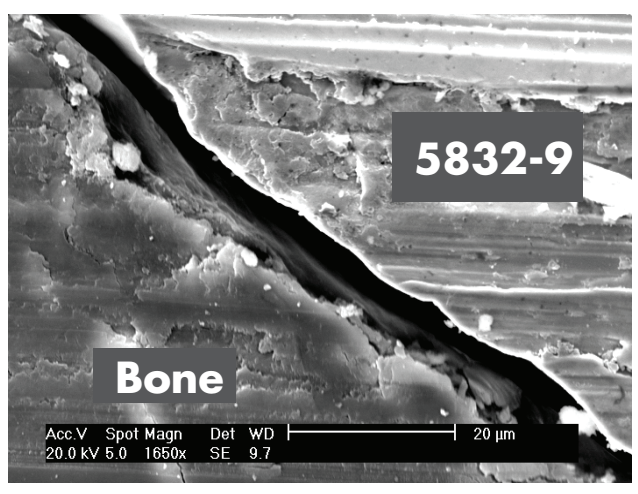

(B)

Figure 5 SEM photomicrographs. (A) bone implant interface Ti6Al4V/control at 1,650x and (B) bone implant interface ISO 5832-9/Control at 1,650x.

Table 3 shows the distances between the implant and the bone of the Control Group, Ti6Al4V and ISO 5832-9, obtained using SEM/EDS software. These distances suggest an absence of implant-bone interaction in the Control Group as compared to the treated groups.

Table 3 Distances (pm) implant-bone interface of Group Control

\begin{tabular}{|l|l|}
\hline \multicolumn{1}{|c|}{ Biomaterial } & \multicolumn{1}{c|}{ Interface/ $\mathbf{~ m ~}$} \\
\hline Ti6Al4V & $3.4 \mathrm{~mm}$ \\
\hline ISO 5832-9 & $6.9 \mathrm{~mm}$ \\
\hline
\end{tabular}

Figures $6 \mathrm{~A}$ and $\mathrm{B}$ show the SEM photomicrographs of implant-bone interface Ti6Al4V/anodic oxide up low potential $(5.0 \mathrm{~V})$ and bone implant interface ISO $5832-9 /$ anodic oxide up low potential $(1.0 \mathrm{~V})$, respectively. The Figure 6A shows the intimate bone apposition of the interface Ti6Al4V/anodic oxide with up to low potential $(5.0 \mathrm{~V})$, where can be observed presence of more mature bone tissue and a uniform bone matrix growing around the implant, with no gap between the biomaterial and the bone. However, in the Figure 6B for ISO 5832-9 can be noted the absence of implant-bone interaction. This aspect was confirmed when the distance between the implant and the bone was measured with a value around $\sim 9.2$ $\mu \mathrm{m}$ (Table 4). Thus, it could be supposed that the Ti6Al4V alloy showed a more effective bone integration response compared to ISO 5832-9 stainless steel with the same electrochemical treatment. These results corroborate with some studies reporting that the presence of an anodic oxide could have a positive effect on the adhesion and proliferation of bone cells (Yun et al., 2010; Zhu et al., 2002). 


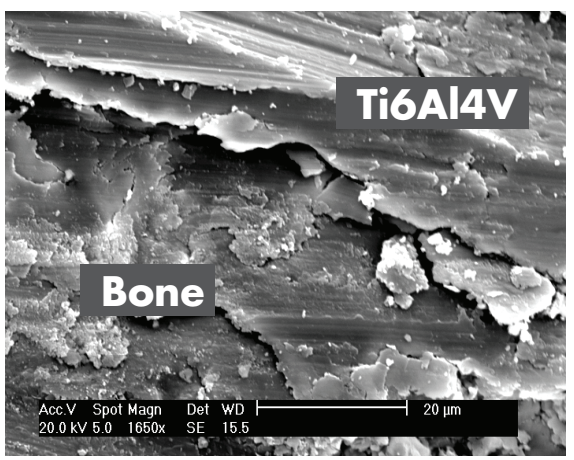

(A)

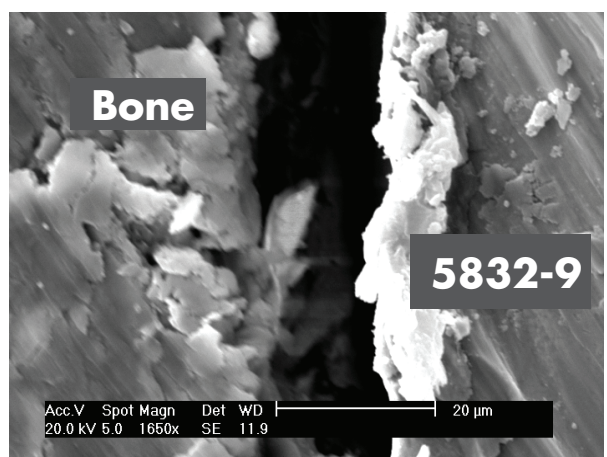

(B)

Figure 6 SEM photomicrographs. (A) bone implant interfaceTi6Al4V/anodic oxide up low potential (5.0 V) at 1,650x and (B) bone implant interface ISO 5832-9/anodic oxide up low potential (1.0 V) at 1,650x, arrow shows the distance between the bone and stainless steel.

Table 4 Distance ( $\mu m)$ implant-bone interface of anodic oxide up low potential.

\begin{tabular}{|l|l|}
\hline \multicolumn{1}{|c|}{ Biomaterial } & \multicolumn{1}{c|}{ Interface/ $\mathbf{~ m m}$} \\
\hline Ti6Al4V/anodic oxide up low potential & 0.0 \\
\hline ISO 5832-9/anodic oxide up low potential & 9.2 \\
\hline
\end{tabular}

Figures 7A and B show the SEM photomicrographs of implant-bone interface of the groups exposed to anodic treatment oxide up to low potential and hydroxyapatite (Hpa) after 10 days of immersion in the SBF solution.

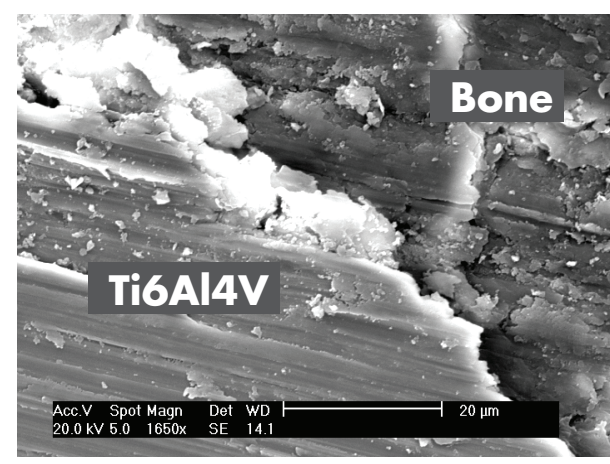

(A)

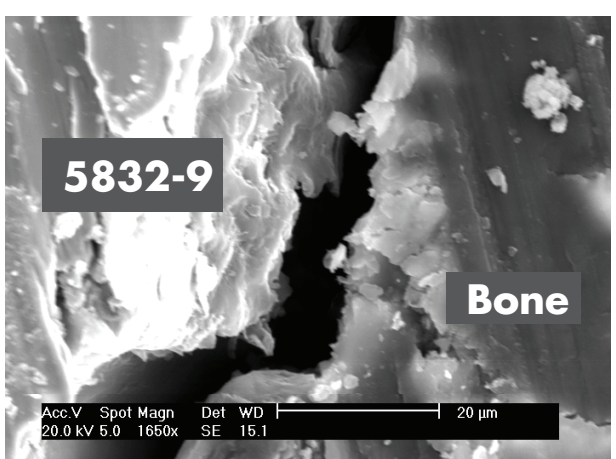

(B)

Figure 7 SEM photomicrographs. (A) bone implant Interface Ti6Al4V anodic oxide up low potential (5.0 V) after immersion in SBF for 10 days at 1,650x and (B) bone implant interface of ISO 5832-9/ anodic oxide up low potential (1.0 V) after immersion in SBF for 10 days at 1,650x, arrow shows the distance between the bone and stainless steel. 
SEM photomicrographs of the implants treated with the anodic oxide up to low potential and Hpa group showed similar behavior to the group exposed only to anodic oxide up to low potential (Figure 7A and B). Ti6Al4V anodic oxide up low potential exhibited the greatest efficiency in the osseointegration process as seen in the direct contact between the bone and the implant (Figure 7A). On the other hand, the ISO 5832-9 stainless steel was less effective than Ti6Al4V (Figure 7B). This means that in the titanium alloy group should have induced more mature bone even when the surface was treated only by electrochemistry. It could indicate that the interaction between the bone and the Ti6Al4V could be explained by the greatest affinity of $\mathrm{TiO}_{2}$ with the bone (Yun et al., 2010; Zhu et al., 2002). In synthesis the surface treated only with oxide growth was sufficient for an effective osseointegration process. Thus, it can be supposed that there is no need for activating the surface with $\mathrm{Ca}$ and $\mathrm{P}$ ions as carried out in the immersion tests. All the ISO 5832-9 groups demonstrated less osseointegration process, suggesting that the Ti6Al4V, with only the presence of $\mathrm{TiO}_{2}$, oxide, exhibited an excellent response in vitro and osseointegration in vivo.

\section{Conclusion}

Bone formation was greater with Ti6Al4V at the surfaces submitted to electrochemical treatment compared to the other groups (control and anodic oxide with up to low potential and Hpa). These results suggest that the anodic treatment could improve the in vivo biological response. Thus, the presence of $\mathrm{TiO}_{2}$ obtained by the potentiodynamic method up to low potentials (thin oxide) on the titanium based orthopedic implants enhanced the osseointegration process.

\section{Acknowledgements}

The authors are grateful to PIPE-UFPR (Graduate Program of Materials Science and Engineering), ISI-SENAI, the Laboratory of Biomaterials and Electrochemistry (Department of Mechanical Engineering/UFPR), the Vivarium (UFPR), the Veterinary Hospital of UFPR, Professor of Odontology Jayme Bordini and Orthopedist Munif Hatem. Finally, we would like to thank CNPq for the productivity fellowship (Grant number 308696/2012-3) awarded to Anna Raquel S. Gomes and Cláudia Eliana Bruno Marino (Grant number 301434/2013-1).

\section{References}

Amini AR, Laurencin CT, Nukavarapu SP. Bone tissue engineering: recent advances and challenges. Crit Rev Biomed Eng. 2012; 40 (5): 363-408. 
Buser D, Nydegger T, Oxland D.L,.et al. Interface shear strength of titanium implants with sandblasted and acid-etched surface: a biomechanical study in the maxilla of miniature pigs, J. Biomed. Mater. Res. 1999; 45:75-83.

Clarke SA, Brooks RA, Lee PT, Rushton N. Bone growth into a ceramic-filled defect around an implant-the response to transforming growth factor beta1, J. Bone Joint Surg. Br. 2004; 86:126-134.

Davies JE, Mendes VC, Ko JC, Ajami E. Topographic scale-range synergy at the functional bone/implant interface. Biomaterials. 2014; 35(1):25-35.

Franco RL, Chiesa R, Oliveira RT, Belo MM, Rosa AL. Bone Response to a Caand P-Enriched Titanium Surface Obtained By Anodization, Braz. Dent. J. 2008; 19:15-20.

Hanawa T, Hiromoto S, Yamamoto A, Kuroda D, Asami K. XPS characterization of the surface Oxide Film of 316L Stainless Steel Samples that was located in Quasi -Biological Environments, Materials Transactions. 2002; 43:3088-3092.

Kokubo T, Miyaji F, Kim HM. Spontaneous Formation of Bonelike Apatite Layer on Chemically Treated Titanium Metals, J. Am.Ceram. Soc. 1996; 79:11271129.

Kokubo T, Takadama H. How useful is SBF in predicting In Vivo bone bioactivity? Biomaterials. 2006; 15: 2907-2915.

Liang B, Fujibayashi S, Neo m, Tamura J, Kim H, Uchida M, kokubo T, Nakamura T. Histological and mechanical investigation of bone-bonding ability of anodically oxidized titanium in rabbits. Biomaterials.2003; 24 (27): 4959-4966.

Lin Z, Wang Y, Wang D, Zhao B, Li J. Porous structure preparation and wettability control on titanium implant, Surf. Coat. Technol. 2013; 228 (1): 131-136.

Liu X, Chu PK. Surface Modification of Titanium, Titanium Alloys and Related Materials for Biomedical Applications, Mater. Sci. Eng. R.2004; 47; 49-121.

Marino CEB, Oliveira EM, Rocha-Filho RC, Biaggio SR. On the stability of thin-anodic-oxide films of titanium in acid phosphoric media, Corr. Sci. 2001; 43:1465-1476. 
Marino CEB, Mascaro LH. EIS characterization of Ti-dental implant in artificial saliva media: dissolution process of the oxide barrier, J. Electroanal. Chem. 2004; 568: 115-120.

Marino CEB, Nascente PAP, Biaggio SR, Rocha-Filho RC, Bocchi N.XPS Characterization of anodic titanium oxide films grown in phosphate buffer solution, Thin Solid Films. 2004; 468:109-112.

Marino CEB, Biaggio SR, Rocha-Filho RC, Bocchi N. Voltammetric stability of anodic films on the Ti6Al4V alloy in chloride medium. Electrochim. Acta. 2006; 51:6580-6588.

Mendes VC, Moineddin R, Davies JE. The effect of discrete calcium phosphate nanocrystals on bone-bonding to titanium surfaces. Biomaterials. 2007; 28(32):4748-55. Epub 2007 Aug 13.

Novaes AB, Souza SLS, Barros RRM, Pereira KKY, Iezz G, Piattelli A. Influence of Implant Surfaces on Osseointegration, Braz. Dent. J. 2010; 21:471-481.

Pulleo DA and Nanci A. Understanding and Controlling the Bone Implant Interface. Biomaterials.1999; 20:2311-2321.

Szesz EM, Pereira BL, Kuromoto NK, Marino CEB, Souza GB, Soares P. Electrochemical and morphology analyses on the titanium surface modified by shot blasting and anodic oxidation processes, Thin Solid Films.2013; 528: 163-166.

Sul Y. The significance of the surface properties of oxidized titanium to the bone response: special emphasis on potential biochemical bonding of oxidized titanium implant. Biomaterials. 2003; 24: 3893-3907.

Villamil RFV, Aranha H, Afonso MLCA, Mercadante MT, Agostinho SML. Aços inoxidáveis em implantes ortopédicos: fundamentos e resistência à corrosão. Rev. Bras. Ortop. 2002; 37, ( 11/12):471-476.

Yang B, Uchida M, Kim HM, Zhang X, Kokubo T. Preparation of bioactive titanium metal by anodic oxidation treatment. Biomaterials.2004; 25: 1003-1010.

Yi Y, Cho P, Al Zaabi A, Addad Y, Jang C. Potentiodynamic polarization behavior for AISI 316L stainless steel in $\mathrm{NaCl}$ solution. Corr. Sci. 2013; 74:92-97. 
Yu WQ, Jiang XQ, Zhang FQ, Xu L. The effect of anatase $\mathrm{TiO}_{2}$ nanotube layers on MC3T3-E1 preosteoblast adhesion, proliferation, and differentiation. J. Biomed. Mater. Res. A. 2010; 94:1012-1022.

Yun K, Yang Y, Lim H, Oh G, Hoh J, Bae I, Kim J, Lee K; Park S. Effect of Nanotubular-micro-roughed titanium Surface on cell response in vitro and osseointegration in vivo. Mater. Sci. Eng. C. 2010; 30: 27-33.

Zhu X, Kim KH, Jeong Y. Anodic oxide films containing Ca and P on Titanium, Biomaterials.2002; 22: 2199-2206. 